\title{
Study on aging properties and degradation mechanism of FRP bars
}

\author{
Wang Meng ${ }^{1 \mathrm{a}}$, Yang Yaqiang ${ }^{2 \mathrm{~b}^{*}}$ \\ ${ }^{1}$ School of Architecture and Civil Engineering, Jiangsu University of Science and Technology, Jiangsu, Dantu District, Zhenjiang, Jiangsu \\ Province, China \\ ${ }^{2}$ School of Architecture and Civil Engineering, Jiangsu University of Science and Technology, Jiangsu, Dantu District, Zhenjiang, Jiangsu \\ Province, China
}

\begin{abstract}
The tensile properties of fiber-reinforced composites (FRP) under various factors of composite aging were studied by tensile test. The test parameters mainly include temperature, salt spray, ultraviolet, rainwater, and stress. The results show that the higher the temperature, the faster the FRP tensile strength decreases; At the same temperature, the ultraviolet radiation has little effect on BFRP bars. Salt spray and rainwater hydrolyze the resin on the surface of the steel bars and expose the inner steel bars. Stress can accelerate the degradation of tensile properties of FRP bars. It has little effect on the elastic modulus of FRP bars. A scanning electron microscope (SEM) was used to observe the changes of steel bars and the mechanism of mechanical property degradation was studied
\end{abstract}

\section{Introduction}

In long-span cable-stayed Bridges, the corrosion of steel cables is the main reason that affects the service life of Bridges. Especially in the offshore areas, long-span cablestayed Bridges are faced with the influence of seawater salt solution or salt spray, rainwater, ultraviolet light, high temperature, and high stress. Due to the characteristics of steel cable material, the span of the cable-stayed bridges is severely limited[1]. However, high-performance FRP cable provides ${ }^{1}$ an effective way to replace steel cable for the construction of a cable-stayed bridge with a larger span due to its characteristics of lightweight, high strength, fatigue resistance, and corrosion resistance [2,3]. Therefore, it is necessary to study the aging properties of FRP bars under various conditions. In this paper, the change of tensile properties of FRP bars was studied through the tensile test, and the influence of temperature, salt spray, rain, ultraviolet ray, and stress level on the tensile strength and tensile elastic modulus of FRP bars was studied. At the same time, the degeneration mechanism of the aged steel bars was studied by scanning electron microscope.

\section{Test design}

\subsection{Test material and parameter setting}

In the experimental study, the nominal diameter of FRP bars was $4 \mathrm{~mm}$, the resin matrix was vinyl ester resin and epoxy resin, the fiber type was carbon fiber and basalt fiber, the volume fiber content was $65 \%$, the surface treatment was winding, the rib spacing was $1 \mathrm{~d}$, the rib depth was $0.06 \mathrm{~d}$, and $\mathrm{d}$ was the nominal diameter of the bars. Test temperature: $35^{\circ} \mathrm{C}$ and $50^{\circ} \mathrm{C}$; The stress applied to the reinforcement is $30 \%-50 \%$ of its ultimate strength. Under the influence of these factors, the aging time was set as $120 \mathrm{~h}, 240 \mathrm{~h}$, and $480 \mathrm{~h}$. Then the tensile properties were tested under the action of multi-factor composite aging.

\subsection{Test design method}

The specimen production refers to ACI440.3R-04 Guide Test Methods for Fiber-Reinforced Polymers (FRPs) for Reinforcing or Strengthening Concrete Structures[4],this is shown in Figure 1. The universal testing machine is used to test the tensile mechanical properties of the FRP tendons after multi-factor composite aging. The displacement-controlled loading method is adopted, and the loading speed is $2 \mathrm{~mm} / \mathrm{min}$.

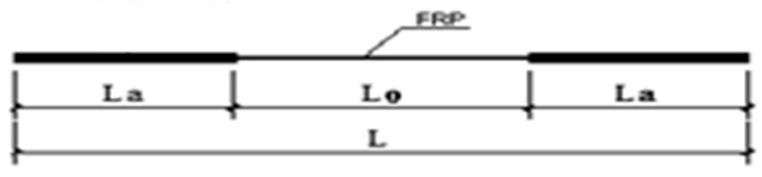

Fig.1 Schematic figure of specimen anchorage

\section{Test results and analysis}

\subsection{Specimen failure shape}

BFRP bars are naturally yellowish-black in color. Under

* Corresponding author: ${ }^{*} 463491645 @ q q . c o m$ 
various conditions, the overall reinforcement can remain intact, but the surface color becomes lighter and lighter because the resin on the surface of the fiber bare leakage caused by shedding.

Tensile tests were carried out on the specimens after aging, and the failure was all tensile failure. The substrate of the reinforcement used in this paper was vinyl ester resin, and its failure shape was a flocculent failure (as shown in Figure 2).

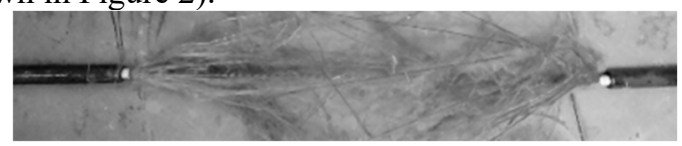

Fig.2 Failure pattern of BFRP bars

\subsection{Test results}

According to the test results, the ultimate load, tensile strength and elastic modulus of the FRP bars are calculated, and the tensile test results of the FRP bars after the test are shown in Table 1. Basalt fiber vinyl ester composite bars
(B-V).

The influence of temperature on the mechanical properties of BFRP bars can be seen from Table 1 and Figure 3 that the strength retention of the bars shows a downward trend. The strength retention rate of the steel at $50^{\circ} \mathrm{C}$ is lower than that at $35^{\circ} \mathrm{C}$ in any period time. Secondly, the intensity retention under $50^{\circ} \mathrm{C}$ was similar to that under UV irradiation, but the intensity retention under UV irradiation was slightly lower. Then, the strength retention rate under salt spray and rainwater is similar, and the strength retention rate under salt spray is slightly lower. Finally, the strength retention rate under applied stress is the lowest among the above conditions. Similarly, it can be seen from Table 1 and Figure 3(b) that, no matter at what temperature, the change value of its elastic modulus fluctuates within a very small range, with little change and no rule to follow. As can be seen from the above, the influence of each influencing condition on the strength retention rate of BFRP bars from large to small is stress, salt spray, rain, ultraviolet, high temperature, and low temperature.

Table 1 Various mechanical properties of BFRP bars after the test

\begin{tabular}{|c|c|c|c|c|c|c|c|c|}
\hline Bar & $\begin{array}{l}\text { Temperature } \\
/{ }^{\circ} \mathrm{C}\end{array}$ & Environment & Time/h & $\begin{array}{l}\text { Ultimate } \\
\text { load /KN }\end{array}$ & $\begin{array}{l}\text { Tensile } \\
\text { strength } \\
/ \mathrm{MPa}\end{array}$ & $\begin{array}{l}\text { Strength } \\
\text { retention } \\
\text { rate } / \%\end{array}$ & $\begin{array}{l}\text { Elastic } \\
\text { Modulus } \\
/ \mathrm{GPa}\end{array}$ & $\begin{array}{l}\text { Elastic } \\
\text { modulus } \\
\text { retention } \\
\text { rate } / \%\end{array}$ \\
\hline \multirow{19}{*}{$\mathrm{B}-\mathrm{V}$} & \multicolumn{3}{|c|}{ Contrast specimen } & 18.47 & 1469.79 & 100.00 & 58.23 & 100.00 \\
\hline & \multirow{3}{*}{$35^{\circ} \mathrm{C}$} & \multirow{3}{*}{-} & 120 & 18.25 & 1452.69 & 98.84 & 57.99 & 99.59 \\
\hline & & & 240 & 18.09 & 1440.25 & 97.99 & 57.85 & 99.35 \\
\hline & & & 480 & 17.59 & 1400.12 & 95.26 & 57.53 & 98.79 \\
\hline & \multirow{15}{*}{$50^{\circ} \mathrm{C}$} & \multirow{3}{*}{-} & 120 & 17.18 & 1367.41 & 93.03 & 57.33 & 98.45 \\
\hline & & & 240 & 16.98 & 1351.62 & 91.96 & 57.13 & 98.11 \\
\hline & & & 480 & 16.51 & 1314.29 & 89.42 & 56.55 & 97.11 \\
\hline & & \multirow{3}{*}{ Salt spray } & 120 & 16.31 & 1298.56 & 88.35 & 57.12 & 98.09 \\
\hline & & & 240 & 15.69 & 1249.47 & 85.01 & 57.82 & 99.29 \\
\hline & & & 480 & 15.46 & 1231.24 & 83.77 & 57.02 & 97.92 \\
\hline & & \multirow{3}{*}{ Ultraviolet } & 120 & 17.11 & 1362.35 & 92.69 & 57.02 & 97.92 \\
\hline & & & 240 & 16.89 & 1344.71 & 91.49 & 57.70 & 99.09 \\
\hline & & & 480 & 16.46 & 1310.76 & 89.18 & 57.47 & 98.69 \\
\hline & & \multirow{3}{*}{ Rainwater } & 120 & 16.36 & 1302.67 & 88.63 & 57.73 & 99.14 \\
\hline & & & 240 & 16.01 & 1274.75 & 86.73 & 57.52 & 98.78 \\
\hline & & & 480 & 15.68 & 1248.29 & 84.93 & 57.67 & 99.04 \\
\hline & & \multirow{3}{*}{ Stress } & 120 & 15.85 & 1261.96 & 85.86 & 57.12 & 99.50 \\
\hline & & & 240 & 15.45 & 1229.77 & 83.67 & 57.94 & 98.78 \\
\hline & & & 480 & 15.08 & 1200.67 & 81.69 & 57.52 & 98.09 \\
\hline
\end{tabular}

(Note: "-" means no other conditions except temperature)

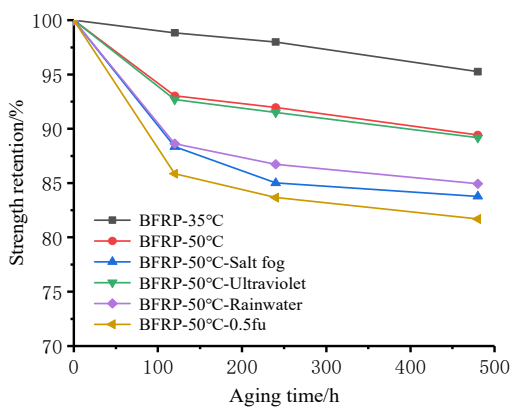

(a) The relationship between strength retention and aging time

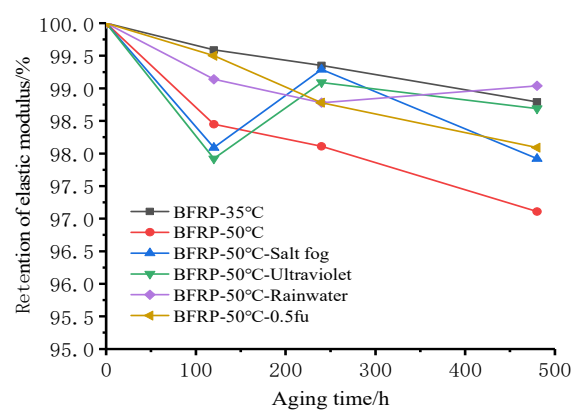

(b) The relationship between the retention of elastic modulus and aging time

Fig.3 Figure of aging test data 


\section{SEM observation of specimen}

A scanning electron microscope (SEM) was used to observe the appearance of time. The degradation of physical and mechanical properties of fiber-reinforced composite bars with time under various conditions was analyzed. The reasons for the degradation of aging properties of BFRP bars were explored according to the data of each group's test results.

\subsection{Observation results}

Because the fiber is not conductive, the reinforcement needs to be "sprayed gold" treatment, and then it is observed, and the reason for the obtained results are analyzed. The specific photos are shown in Fig. 4 below.
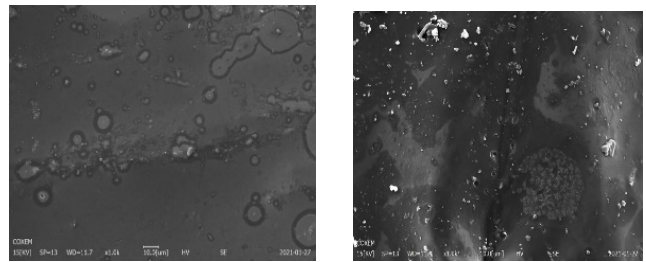

(a) $35^{\circ} \mathrm{C}-1000$ times-surface (b) $50^{\circ} \mathrm{C}-1000$ times - surface
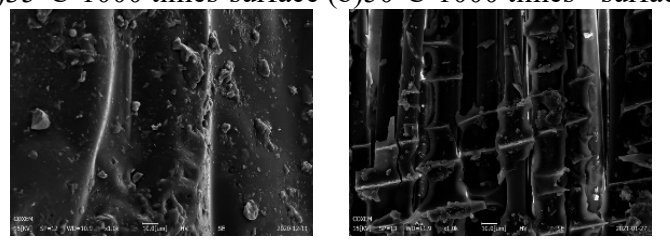

(c) $50^{\circ} \mathrm{C}$ - UV -1000 times - surface $(\mathrm{d}) 50^{\circ} \mathrm{C}$-salt spray- 1000 times-surface
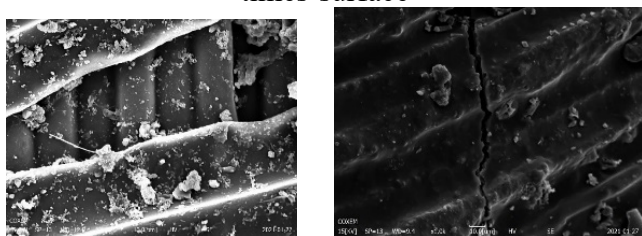

(e) $50^{\circ} \mathrm{C}$-rainwater- 1000 times-surface (f) $50^{\circ} \mathrm{C}-0.5 \mathrm{fu}-1000$ times-surface

Fig.4 Scanning electron microscope figures of specimens

\subsection{Analysis of Observation Results}

As can be seen from Fig. 4 (a), (b), and (c) above under each test condition, the surface of the specimen bars at $35^{\circ} \mathrm{C}, 50^{\circ} \mathrm{C}$, and under UV conditions was not damaged and the internal fibers were well protected. In the condition of salt spray and rain, most of the surface resins of the steel bars are hydrolyzed, exposing the internal fibers. The main internal stressed fibers are in direct contact with the external environment, which has a certain influence on its mechanical properties, as shown in Fig. 4 (d) and (e). In the stress environment, the surface of the reinforcement remains intact. However, there are subtle cracks (as shown in Fig. 4 (f)) on the surface of the reinforcement caused by the applied stress. The external adverse conditions enter the interior of the reinforcement through the cracks, affecting its mechanical properties. However, it can be seen from Figure 4 that its fiber is intact without being damaged, so it can explain why its elastic modulus does not change much under any conditions.

\section{Conclusions}

This chapter conducts aging tests on BFRP bar specimens under various conditions, including two temperatures of $35^{\circ} \mathrm{C}$ and $50^{\circ} \mathrm{C}$, aging environments such as salt spray, ultraviolet rays, rain, and stress, and three aging times of $120 \mathrm{~h}, 240 \mathrm{~h}$, and $480 \mathrm{~h}$. After aging under various conditions, the specimens were subjected to uniaxial tensile test and SEM observation. Combine the photos taken by the scanning electron microscope to give a reasonable explanation. The conclusions obtained from the experiments in this chapter mainly have the following points.

(1) In the unidirectional tensile test after aging under various conditions, the failure mode of the specimen is the same as that of the conventional material test specimen, and there is no obvious change.

(2) Under what temperature conditions, the tensile strength retention rate of BFRP bars decreases with the increase of aging time.

(3) Regardless of the aging time, the strength retention rate at high test temperature is always lower than that at low temperature.

(4) No matter under what aging conditions or aging time, the elastic modulus does not change much, and the elastic modulus measured after aging has no obvious rule of change.

(5) Under the same temperature, each aging condition has a descending effect on the strength of the reinforcement: stress, salt spray, rain,and ultraviolet light.

\section{Acknowledgments}

The author wish to acknowledge the financial support from Postgraduate. National Natural Science Foundation of China (No.51808265), Shandong Provincial Key Research and Development Program (No.2019GSF111013), Natural Science Research Program of Higher Education of Jiangsu Province (No.18KJB560005)

\section{References}

1. Jiang, J.Y, Cui, Y, Mei, K.H, Wu, G, Zhang, M.(2006) The key technology of the first CFRP cable-stayed bridge in China. J. Highway Traffic Science and Technology, (02): 111-114+122.

2. Li, C.C, Gao, D.Y, Wang, Y.L, Tang, J.Y(2017) Effect of high temperature on the bond performance between basalt fiber reinforced polymer (BFRP) bars and concrete. J. CONSTR BUILD MATER,141:44-51.

3. Feng, P, Ye, L.P, Jin, F.F, Q, Y.J, (2011). Mechanical performance and design method of FRP bridge structure. In: Composite Bridge Technology Seminar. Beijing.pp.8.

4. Rizkalla, S.H, Busel, J.P. (2004) ACI440.3R04.G.T.M.F. Guide Test Methods for Fiber- 
Reinforced Polymers (FRPs ) for Reinforcing or Strengthening Concrete Structures, Farmington Hills,
MI. 